\title{
Development of Standards for Analytical Filter Papers
}

\author{
By Bourdon W. Scribner and William K. Wilson
}

\begin{abstract}
Filter papers used for ordinary qualitative and quantitative analyses were treated to obtain data for recommended standards of quality. The papers comprised the products of two domestic and three foreign manufacturers.

Tests were made for retention of fine precipitates, time of flow of water, ash, and wet bursting strength by modified methods developed at the Bureau. Density, alpha-cellulose, copper number, and acidity were also determined. Instances of filter paper becoming too brittle for use through deterioration have been observed. Stable papers are characterized by a high content of alpha-cellulose, a low copper number, and low acidity. Furthermore, the degraded cellulose of deteriorated filter papers may cause erroneous analytical results.

The ash, bursting strength, density, and time of flow of water varied considerably for papers made for the same stated use. The alpha cellulose content and copper number also varied considerably in papers made by different manufacturers. The acidity of all the papers was low. The papers showed a correlation between density and time of flow of water.

Data are given showing the much greater decrease in alpha-cellulose and increase in copper number of papers of poor condition of cellulose than of papers of good quality of cellulose when subjected to accelerated aging. Data are also included on the poor condition of cellulose in deteriorated paper as compared with paper that had not deteriorated. Degraded cellulose is soluble in alkaline solutions and to some extent in water, and examples are given of how this may affect analyses.

Recommended standards are given for the properties considered of the most importance: alpha-cellulose, copper number, acidity, ash, bursting strength, and time of flow of water.
\end{abstract}

\section{Introduction}

An investigation directed toward the development of recommended standards for analytical filter papers was undertaken by the National Bureau of Standards in 1942. The investigation was prompted by the lack of adequate testing methods for the valuation of such papers and the nonexistance of recognized standards of quality.

The need for such information was acute at the time because the war had caused curtailment of supply of foreign-made papers. Thus induced American manufacture of the higher grades not heretofore produced in this country, and in lieu of the extensive experience with the foreign products, means had to be found quickly to evaluate the new domestic products. Testing methods were involved that were adequate for comparison of the quality of foreign and domestic products. In a short time the Bureau was able to report that the new American products compared very favorably with those made abroad and, therefore, that no shortage of satisfactory filter paper was anticipated.

The study of the testing methods was continued until they were considered suitable to serve as standard testing procedures. The results of this work have been published. In order to develop standards of quality, these methods were then used to make extensive tests of filter papers of both foreign and domestic manufacture, the results of which are reported in this paper.

\section{Papers Tested}

Newly made papers, representative of the various kinds and grades used for ordinary analyt- 
ical work, were tested. They were the products of the following companies: Domestic: Carl Schleicher \& Schuell Co. ("S \& S"); Eaton-Dikeman Co. ("ED"). Foreign: W. \& R. Balston, Ltd., England ("Whatman"); J. Barcham Green \& Son, England ("J. Green"); Grycksbo Papersbruck A. B., Sweden ("Munktell"). Tests were also made on some old papers that had deteriorated, relative to the correlation of degraded cellulose with aging quality and to the effects of degraded cellulose on chemical analyses in which deteriorated papers are used.

In the tables of test data, the papers are identified only with respect as to whether they are of domestic or of foreign manufacture. The manufacturers of the papers are not identified, because these data may not be representative of their later products. The domestic papers were machine-made and the foreign papers were handmade.

\section{Testing Methods}

Tests were made by improved methods developed at the Bureau for retention of barium sulfate, time of flow of water through the papers, and content of ash. ${ }^{2}$ The bursting strength of wet paper was determined by a modification of the standard method T403m of the Technical Association of the Pulp and Paper Industry (TAPPI) for dry paper. The following methods of the association were used for the other tests made: Thickness $(\mathrm{T} 411 \mathrm{~m})$ and weight in grams per square meter (T410m). Density was calculated from these values. Alpha-cellulose (T429m), copper number (T430m) and acidity as $\mathrm{pH}$ $(\mathrm{T} 435 \mathrm{~m})$. These are related to the condition of the cellulose and the stability of paper.

The foregoing methods served as a basis for a

\footnotetext{
${ }_{1} \mathrm{H}$. Bogaty and F. T. Carson, Measurement of rate of flow of water through filter paper, J. Research NBS 33, 353 (1944) RP1613.

${ }^{2}$ B. W. Scribner and W. K. Wilson, Methodsi or the evaluation of filter papers, J. Research NBS 34, 453 (1945) RP1653.
}

suggested TAPPI method for the evaluation of filter papers. ${ }^{3}$

An accelerated aging test, used as a measure of deterioration of the papers that might occur in storage, was made by the TAPPI method T453m, heat-test for relative stability of paper. The test is made by heating the paper for $72 \mathrm{hr}$ at $100^{\circ} \mathrm{C}$

\section{Test Data for Newly Made Papers}

Test data for newly made analytical filter papers are contained in tables $1,2,3$, and 4 . The papers are classified in the tables according to the manufacturers' descriptions. The quality of the majority of the papers, with respect to the condition of the cellulose and the acidity, was very good. Stable papers are characterized by a high content of alpha-cellulose and low acidity. Strudies at the Bureau of the deterioration of papers ${ }^{4}$ have shown that the content of alphacellulose and the copper number are good criteria of the condition of the cellulose of paper fibers relative to the stability of papers. Alpha-cellulose is that part of the cellulose that is insoluble in a strong solution of sodium hydroxide under definitely prescribed conditions. It is a measure of the unmodified fraction of the cellulose. The copper number designates the amount of copper precipitated as cuprous oxide by cellulose under definitely specified conditions from a solution of copper sulfate. It is a measure of the amount of unstable modified forms of cellulose present. An alphacellulose content of not less than 95 percent, a copper number of not more than 1.0, and an acidity equivalent to a $\mathrm{pH}$ value of not less than 5.0 , are required in the Federal Government specifications for permanent record papers. The effects of degraded cellulose in filter paper on chemical analysis are discussed in the following section.

\footnotetext{
3 Testing analytical filter papers, T471sm.

4 A. E. Kimberly and B. W. Seribner, Summary report of National Bureau of Standards research on preservation of records, NBS Misc. Pub. M154
} (1937). 
TABLE 1.-Test data on unwashed ${ }^{1}$ analytical papers

\begin{tabular}{|c|c|c|c|c|c|c|c|c|c|c|c|}
\hline \multirow{2}{*}{ Sample ${ }^{2}$ designation } & \multirow{2}{*}{$\begin{array}{l}\text { Alpha- } \\
\text { cellulose }\end{array}$} & \multirow{2}{*}{$\begin{array}{l}\text { Copper } \\
\text { number }\end{array}$} & \multirow{2}{*}{$\begin{array}{l}\mathrm{pH}, \text { hot } \\
\text { extration }\end{array}$} & \multirow{2}{*}{ Ash } & \multirow{2}{*}{$\begin{array}{l}\text { Ash per } \\
\text { 11-cm } \\
\text { circle }\end{array}$} & \multirow{2}{*}{$\begin{array}{l}\text { Bursting } \\
\text { strength, } \\
\text { wet }\end{array}$} & \multirow{2}{*}{ Weight } & \multirow{2}{*}{$\begin{array}{l}\text { Thick- } \\
\text { ness }\end{array}$} & \multirow{2}{*}{ Density } & \multicolumn{2}{|c|}{ Time of flow of water } \\
\hline & & & & & & & & & & A verage & Range \\
\hline \multicolumn{12}{|c|}{ PAPERS FOR COARSE PRECIPITATES } \\
\hline $\mathrm{A} 1$ & $\begin{array}{r}\text { Percent } \\
97\end{array}$ & 0.2 & 7.3 & $\begin{array}{r}\text { Percent } \\
0.035\end{array}$ & $\begin{array}{l}m g \\
0.45\end{array}$ & $\begin{array}{r}\text { Points } \\
7.5\end{array}$ & $\begin{array}{l}g / m^{2} \\
140.0\end{array}$ & in. & $\mathrm{g} / \mathrm{cm}^{3}$ & $\mathrm{sec}$ & $\sec$ \\
\hline $\mathrm{A} 2$ & 97 & .3 & 7.3 & .040 & .35 & 3. 0 & $\begin{array}{r}140.0 \\
83.5\end{array}$ & $\begin{array}{r}0.0188 \\
.0086\end{array}$ & $\begin{array}{r}0.40 \\
.38\end{array}$ & $\begin{array}{l}14 \\
11\end{array}$ & $\begin{aligned} 11 \text { to } 16 . \\
9 \text { to } 13 .\end{aligned}$ \\
\hline B1 ... & 97 & 4 & 7.1 & .045 & .40 & 4. $2 \hat{\varepsilon}$ & 87.5 & .0072 & .48 & 11 & 10 to 13 . \\
\hline E1 & $86^{\circ}$ & 1.7 & 6.7 & .24 & 1.9 & 2. 5 & 85.0 & .0104 & .32 & 14 & 10 to 17 . \\
\hline F1 & 97 & 0.2 & 7.4 & .075 & 0.50 & 5. 25 & 73.0 & .0074 & .39 & 23 & 20 to 29. \\
\hline $\mathrm{F} 2$ & 95 & .4 & 7.0 & .040 & .25 & 6. 25 & 68.1 & .0064 & .42 & 21 & 18 to 24 . \\
\hline F3 & 97 & .1 & 7.5 & .075 & .55 & 3.5 & 84. 9 & .0074 & .45 & 20 & 17 to 23 . \\
\hline \multicolumn{12}{|c|}{ PAPERS FOR MEDIUM PRECIPITATES } \\
\hline A3 & 97 & 0.2 & 7.4 & 0.045 & 0.35 & 3.5 & 84.0 & 0.0080 & 0.41 & 34 & 25 to 43 . \\
\hline B2 _. & 97 & .3 & 7.0 & .040 & .30 & 2. 25 & 81.8 & .0066 & .49 & 29 & 25 to 32 . \\
\hline B3 ... & 97 & .2 & 7.0 & .035 & .30 & 3.0 & 95.8 & .0072 & .52 & 48 & 44 to 56. \\
\hline B4 & 97 & .3 & 7.3 & .10 & 1.7 & 7.25 & 180.0 & .0146 & .49 & 41 & 34 to 48 . \\
\hline B5 ... & 97 & .2 & 8.9 & .15 & 1.1 & 3. 0 & 84. 2 & .0074 & .45 & 19 & 74 to 91. \\
\hline $\mathrm{E} 2$. & 88 & 1. 2 & 6.7 & .055 & 0.30 & 3. 75 & 58.7 & .0046 & .50 & 22 & 16 to 30. \\
\hline E3. & 87 & 1.1 & 6.5 & .065 & .35 & 2. 25 & 59.7 & .0056 & .42 & 45 & 35 to 54 . \\
\hline E4_. & 85 & 1.3 & 6.7 & .060 & .40 & 3. 0 & 71.7 & .0070 & .40 & 29 & 20 to 38 . \\
\hline E5 . & 90 & 1. 2 & 6.8 & .065 & .55 & 3. 0 & 93.4 & .0096 & .38 & 21 & 19 to 25 . \\
\hline $\mathrm{F} 4 \ldots$ & 97 & 0.1 & 7.3 & .10 & .7 & 5. 75 & 72.9 & .0056 & .51 & 48 & 34 to 67 . \\
\hline F5 & 97 & .2 & 7.6 & .085 & .65 & 7. 25 & 83.0 & .0064 & .51 & 45 & 37 to 54 . \\
\hline $\mathrm{F} 6 \ldots$ & 91 & .6 & 8.4 & .28 & 3.4 & 9. 25 & 129.3 & .0122 & .42 & 23 & 16 to 32 . \\
\hline F7 . & 92 & .7 & 6.4 & .10 & 0.9 & 6.75 & 99.3 & .0088 & .44 & 40 & 28 to 42 . \\
\hline F8 & 96 & .2 & 7.2 & .055 & .35 & 5. 75 & 69.9 & .0080 & .34 & 24 & 19 to 27 . \\
\hline F9 & 95 & .2 & 7.4 & .12 & .8 & 5. 0 & 72.0 & .0060 & .47 & 44 & 37 to 52 . \\
\hline \multicolumn{12}{|c|}{ PAPERS FOR FINE PRECIPITATES } \\
\hline A4 $\ldots$ & 97 & 0.3 & 7.1 & 0.030 & 0.25 & 4. 25 & 85.6 & 0.0068 & 0.49 & 79 & \\
\hline B6 & 97 & .2 & 7.6 & .10 & .9 & 5. 0 & 98.6 & .0078 & .50 & 81 & 74 to 91 . \\
\hline $\mathrm{C} 1 \ldots$ & 89 & .7 & 8.8 & .29 & 1.8 & 5. 0 & 69.3 & .0058 & .47 & 61 & 51 to 71 . \\
\hline $\mathrm{C} 2 \ldots$ & 90 & .9 & 8.5 & .49 & 4. 2 & 5. 75 & 93.0 & .0090 & .41 & 60 & 43 to 71 \\
\hline Fi0 $\ldots$ & 97 & .1 & 7.0 & .10 & 0.7 & 6. 25 & 74.5 & .0058 & .51 & 107 & 88 to 123 . \\
\hline
\end{tabular}

Not washed with acid.

2 Papers designated with the same letter are of the same manufacturer. The papers designated $\mathrm{A}$ and $\mathrm{F}$ are of domestic manufacturers.

TABLE 2.- Test data on single acid-washed ${ }^{1}$ analytical filter papers

\begin{tabular}{|c|c|c|c|c|c|c|c|c|c|c|c|}
\hline \multirow{2}{*}{ Sample designation } & \multirow{2}{*}{$\begin{array}{l}\text { Alpha- } \\
\text { cellulose }\end{array}$} & \multirow{2}{*}{$\begin{array}{l}\text { Copper } \\
\text { number }\end{array}$} & \multirow{2}{*}{$\begin{array}{l}\mathrm{pH}, \text { hot } \\
\text { extraction }\end{array}$} & \multirow{2}{*}{ Ash } & \multirow{2}{*}{$\begin{array}{l}\text { Ash per } \\
\text { 11-cm } \\
\text { circle }\end{array}$} & \multirow{2}{*}{$\begin{array}{l}\text { Bursting } \\
\text { strength, } \\
\text { wet }\end{array}$} & \multirow{2}{*}{ Weight } & \multirow{2}{*}{$\begin{array}{l}\text { Thick- } \\
\text { ness }\end{array}$} & \multirow{2}{*}{ Density } & \multicolumn{2}{|c|}{ Time of flow of water } \\
\hline & & & & & & & & & & Average & Range \\
\hline
\end{tabular}

PAPERS FOR COARSE PRECIPITATES

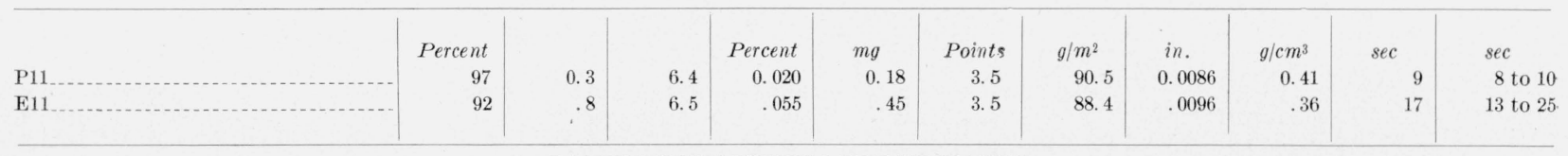

PAPERS FOR MEDIUM PRECIPITATES

\begin{tabular}{|c|c|c|c|c|c|c|c|c|c|c|c|}
\hline $\begin{array}{l}\mathrm{B} 12 \\
\mathrm{E} 12\end{array}$ & $\begin{array}{l}97 \\
89\end{array}$ & $\begin{array}{l}0.2 \\
1.4\end{array}$ & $\begin{array}{l}6.4 \\
6.8\end{array}$ & $\begin{array}{r}0.014 \\
.060\end{array}$ & $\begin{array}{r}0.13 \\
.35\end{array}$ & $\begin{array}{l}4.5 \\
2.5\end{array}$ & $\begin{array}{l}87.5 \\
60.1\end{array}$ & $\begin{array}{r}0.0078 \\
.00666\end{array}$ & $\begin{array}{r}0.44 \\
.36\end{array}$ & $\begin{array}{l}38 \\
24\end{array}$ & $\begin{array}{l}31 \text { to } 41 \\
16 \text { to } 36\end{array}$ \\
\hline \multicolumn{12}{|c|}{ PAPER FOR FINE PRECIPITATES } \\
\hline B13. & 96 & 0.4 & 6.2 & 0.015 & 0.11 & 6.75 & 88.0 & 0.0068 & 0.51 & 120 & 107 to 149 \\
\hline
\end{tabular}

${ }^{1}$ Papers washed with hydrochloric acid. 
TABLE 3.-Test data on double acid-washed ${ }^{1}$ analyitical filter papers

\begin{tabular}{|c|c|c|c|c|c|c|c|c|c|c|c|}
\hline \multirow{2}{*}{ Sample designation } & \multirow{2}{*}{$\begin{array}{l}\text { Alpha- } \\
\text { cellulose }\end{array}$} & \multirow{2}{*}{$\begin{array}{l}\text { Copper } \\
\text { number }\end{array}$} & \multirow{2}{*}{$\begin{array}{l}\mathrm{pH}, \text { hot } \\
\text { extraction }\end{array}$} & \multirow{2}{*}{ Ash } & \multirow{2}{*}{$\begin{array}{l}\text { Ash per } \\
\text { 11-cm } \\
\text { circle }\end{array}$} & \multirow{2}{*}{$\begin{array}{l}\text { Bursting } \\
\text { strength, } \\
\text { wet }\end{array}$} & \multirow{2}{*}{ Weight } & \multirow{2}{*}{$\begin{array}{l}\text { Thick- } \\
\text { ness }\end{array}$} & \multirow{2}{*}{ Density } & \multicolumn{2}{|c|}{ Time of flow of water } \\
\hline & & & & & & & & & & A verage & Range \\
\hline
\end{tabular}

PAPERS FOR COARSE PRECIPITATES

\begin{tabular}{|c|c|c|c|c|c|c|c|c|c|c|c|}
\hline A 21. & $\begin{array}{r}\text { Percent } \\
93\end{array}$ & 1. 2 & 6. 8 & $\begin{array}{r}\text { Percent } \\
0.006\end{array}$ & $\begin{array}{l}m g \\
0.08\end{array}$ & $\begin{array}{c}\text { Points } \\
11.0\end{array}$ & $\begin{array}{l}g / m^{2} \\
152.5\end{array}$ & $\begin{array}{l}\text { in. } \\
0.0142\end{array}$ & $\begin{array}{l}g / m^{3} \\
0.42\end{array}$ & $\stackrel{s e c}{15}^{s}$ & $\begin{array}{l}\mathrm{sec} \\
10 \text { to } 18\end{array}$ \\
\hline A 22 & 97 & 0.3 & 6.5 & .005 & .03 & 19.5 & 64.5 & .0068 & .37 & 10 & 9 to 11 \\
\hline A $23 \ldots \ldots \ldots$ & 96 & .5 & 6. 1 & .007 & .05 & 5. 0 & 91.7 & .0088 & .41 & 16 & 15 to 17 \\
\hline $\mathrm{B} 21 \ldots \ldots$ & 97 & .2 & 6.3 & .012 & .10 & 3.5 & 92.0 & .0092 & .39 & 9 & 8 to 10 \\
\hline $\mathrm{C} 21$ & 88 & 1. 2 & 6. 7 & .020 & .15 & 6. 0 & 75.8 & .0074 & .40 & 29 & 19 to 36 \\
\hline
\end{tabular}

PAPERS FOR MEDIUM PRECIPITATES

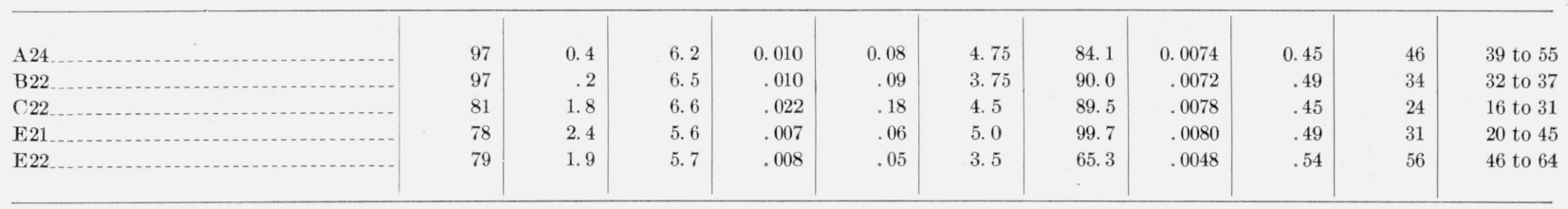

PAPERS FOR FINE PRECIPITATES

\begin{tabular}{|c|c|c|c|c|c|c|c|c|c|c|c|}
\hline A 25 & 96 & 0.5 & 6. 0 & 0.008 & 0.06 & 5. 0 & 88.4 & 0.0064 & 0.54 & 220 & 165 to 288 \\
\hline A26 & 96 & .3 & 6. 3 & .007 & .06 & 4. 0 & 86. 7 & .0066 & .52 & 145 & 125 to 159 \\
\hline B23 & 96 & .4 & 6. 3 & .011 & .10 & 6.0 & 97.5 & .0088 & .44 & 137 & 125 to 150 \\
\hline B24 _..... & 97 & .3 & 6. 1 & .011 & .08 & 4. 25 & 75. 2 & .0068 & .43 & 126 & 106 to 160 \\
\hline $\mathrm{C} 23 \ldots \ldots \ldots$ & 92 & .7 & 6.3 & .040 & .30 & 5. 0 & 89.9 & .0072 & .49 & 79 & 55 to 111 \\
\hline E23 & 80 & 1.9 & 6.3 & .020 & .13 & 2. 25 & 62.7 & .0048 & .51 & 71 & 62 to 82 \\
\hline
\end{tabular}

1 Washed with hydrochloric and hydrofluoric acid.

TABLE 4.-Test data on hardened ${ }^{1}$ analytical filter papers

\begin{tabular}{|c|c|c|c|c|c|c|c|c|c|c|c|}
\hline \multirow{2}{*}{ Sample designation } & \multirow{2}{*}{$\begin{array}{l}\text { Alpha- } \\
\text { cellulose }\end{array}$} & \multirow{2}{*}{$\begin{array}{l}\text { Copper } \\
\text { number }\end{array}$} & \multirow{2}{*}{$\begin{array}{l}\mathrm{pH}, \text { hot } \\
\text { extraction }\end{array}$} & \multirow{2}{*}{ Ash } & \multirow{2}{*}{$\begin{array}{l}\text { Ash per } \\
\text { 11-cm } \\
\text { circle }\end{array}$} & \multirow{2}{*}{$\begin{array}{l}\text { Burst- } \\
\text { ing } \\
\text { strength, } \\
\text { wet }\end{array}$} & \multirow{2}{*}{ Weight } & \multirow{2}{*}{$\begin{array}{c}\text { Thick- } \\
\text { ness }\end{array}$} & \multirow{2}{*}{ Density } & \multicolumn{2}{|c|}{ Time of flow of water } \\
\hline & & & & & & & & & & Average & Range \\
\hline
\end{tabular}

PAPERS FOR COARSE PRECIPITATES

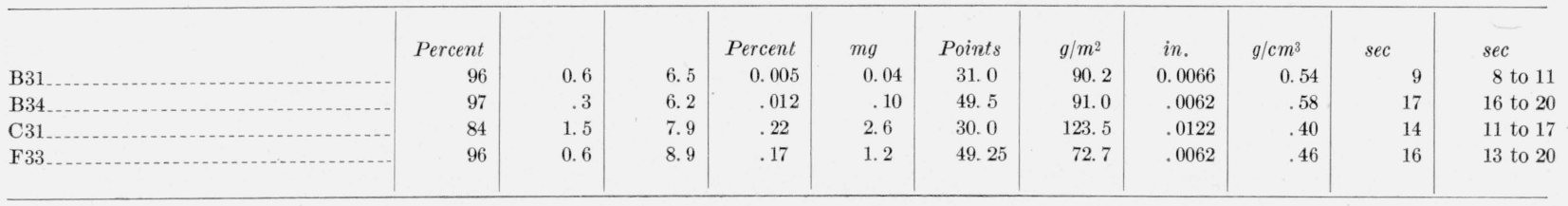

PAPERS FOR MEDIUM PRECIPITATES

\begin{tabular}{|c|c|c|c|c|c|c|c|c|c|c|c|}
\hline B33 .... & 97 & 0.4 & 6.3 & 0.018 & 0.16 & 47.5 & 96.8 & 0.0064 & 0.59 & 36 & 28 to 44 \\
\hline F31 _... & 96 & .3 & 9.0 & .74 & 6.5 & 68.75 & 95.7 & .0070 & .54 & 40 & 32 to 46 \\
\hline F32 & 97 & .2 & 9.3 & .25 & 1.8 & 49.0 & 80.0 & .0070 & .45 & 21 & 16 to 27 \\
\hline
\end{tabular}

PAPERS FOR FINE PRECIPITATES

\begin{tabular}{|c|c|c|c|c|c|c|c|c|c|c|c|}
\hline A 31. & 97 & 0.2 & 6.7 & 0.020 & 0.15 & 139.0 & 80.8 & 0.0038 & 0.84 & 259 & 236 to 284 \\
\hline B32 _. & 97 & .4 & 6.4 & .011 & .10 & 61.25 & 97.4 & .0046 & .83 & 132 & 115 to 189 \\
\hline
\end{tabular}

1 Hardened by treatment with acid or other special treatment. 
The ash, bursting strength, weight, thickness, density, and time of flow of water varied considerably for papers made for the same stated use. With few exceptions, papers made for fine precipitates retained completely a barium sulfate precipitate prepared under specified conditions. ${ }^{5}$

A relation between time of flow of water and density of paper is to be expected.

The data show that density has an important bearing on the time of flow, but that it is not always a dominating factor.

\section{Effects of Degraded Cellulose in Chemical Analysis}

As mentioned in section VI, when a sample of cellulose is treated in a definitely prescribed manner with a strong solution of sodium hydroxide and filtered, the insoluble portion is defined as alpha-cellulose. The filtrate contains the socalled beta- and gamma-fractions. The portion that precipitates when the filtrate is acidified with a strong mineral acid is defined as the beta-fraction, and that which remains in solution is called the gamma-fraction. Although the test is an empirical one, it gives some very practical information about cellulose.

For the purpose of this discussion, degraded cellulose is defined as the beta- and gamma-fractions and contains oxidized and/or hydrolyzed cellulose. The beta-fraction is almost always larger than the gamma, and in any process that results in an increase of degraded cellulose, the increase is predominantly in the beta-fraction. This is indicated by the data in table 5 for some filter papers that had been subjected to accelerated aging by heating for $72 \mathrm{hr}$ at $105^{\circ} \mathrm{C}$. This same increase in beta-cellulose rather than in gammacellulose has been noted at the Bureau in work on the accelerated aging and also natural aging of other papers of known history. Some data on the condition of the cellulose of nondeteriorated and deteriorated filter papers that had not been subjected to accelerated aging are contained in table 6 . The deteriorated papers were so brittle as to be unfit for use.

High-grade analytical filter papers are usually made from fibers having a high alpha-cellulose content, generally from cotton or linen cuttings of textile mills. The cellulose, however, may be

${ }^{5}$ See footnote 2.
TABLE 5.-Effect of accelerated aging ${ }^{1}$ on cellulose of filter papers ${ }^{2}$

\begin{tabular}{|c|c|c|c|c|c|c|c|c|}
\hline \multicolumn{2}{|c|}{ Alpha-cellulose } & \multicolumn{2}{|c|}{ Beta-cellulose } & \multicolumn{2}{|c|}{$\begin{array}{c}\text { Gamma-cellu- } \\
\text { lose }\end{array}$} & \multicolumn{2}{|c|}{$\begin{array}{l}\text { Copper num- } \\
\text { ber }\end{array}$} & \multirow{2}{*}{$\begin{array}{l}\text { pH, } \\
\text { hot } \\
\text { extrac- } \\
\text { tion }\end{array}$} \\
\hline Original & Change & $\begin{array}{l}\text { Origi- } \\
\text { nal }\end{array}$ & Change & $\begin{array}{c}\text { Origi- } \\
\text { nal }\end{array}$ & Change & $\begin{array}{l}\text { Origi- } \\
\text { nal }\end{array}$ & Change & \\
\hline $\begin{array}{r}\text { Percent } \\
95.8\end{array}$ & -3.0 & $\begin{array}{c}\text { Percent } \\
3.4\end{array}$ & 3.3 & $\begin{array}{c}\text { Percent } \\
0.8\end{array}$ & -0.3 & 0.5 & 0.2 & 6.0 \\
\hline 96.3 & -3.1 & 3.1 & 3.3 & .6 & -.2 & .3 & .1 & 6.3 \\
\hline 95.8 & -1.5 & 3.3 & 1.8 & .9 & -.3 & .4 & .1 & 6.3 \\
\hline 97.3 & -1.9 & 2.1 & 1. 6 & .6 & .3 & .3 & .1 & 6. 1 \\
\hline 89.0 & -7.5 & 10. 2 & 7.3 & .8 & .2 & 1.4 & .4 & 6.8 \\
\hline 77.8 & -8.3 & 21.4 & 8.2 & .8 & .1 & 2.4 & .3 & 5. 6 \\
\hline 80.5 & -8.4 & 18.4 & 8.5 & 1.1 & -.1 & 2.0 & .7 & 6. 6 \\
\hline 86. 2 & -12.0 & 12. 7 & 12.1 & 1.1 & -.1 & 1.5 & .5 & 6. 7 \\
\hline
\end{tabular}

Heated $72 \mathrm{hr}$ at $105^{\circ} \mathrm{C}$.

${ }^{2}$ All acid-washed. Each pair of values are for papers of different manufacturers

TABLE 6.-Condition of cellulose in nondeteriorated and deteriorated filter papers ${ }^{1}$

\begin{tabular}{|c|c|c|c|}
\hline \multirow{2}{*}{ Condition of paper } & \multirow{2}{*}{$\begin{array}{l}\text { Nonde- } \\
\text { teriorated }\end{array}$} & \multicolumn{2}{|c|}{ Deteriorated } \\
\hline & & Sample 1 & Sample 2 \\
\hline Alpha-cellulose, $\%$ & 97.3 & 68.8 & 65.3 \\
\hline Beta-cellulose, \% & 1. 7 & 30.7 & 34.1 \\
\hline Gamma-cellulose, \% & 1.0 & 0.5 & 0.6 \\
\hline Copper number....... & 0.2 & 2. 8 & 3. 2 \\
\hline
\end{tabular}

1 Papers of the same kind and manufacturer.

damaged by improper treatment during the manufacturing process. The papers that have been washed with acid to reduce the ash content may suffer if the acid treatment is not carefully controlled, or if the acid is not carefully washed out of the fibers after treatment.

With the above information as a basis, filter paper can be discussed with respect to the effect of degraded cellulose in chemical analysis, a subject that heretofore has been given little attention. Degraded cellulose in filter papers may cause erroneous analytical results because it is partially soluble in any alkaline solution, and to a lesser extent, in hot water, in cold water, and dilute acids. If a filtrate contained beta-cellulose, this fraction would be precipitated if the solution were acidified. If an analytical precipitation were subsequently carried out in acid medium and the precipitate dried and weighed without ignition, the weight would be too high. If a filtrate containing soluble cellulose were evaporated to dryness and the residue weighed, the weight would include the soluble cellulose. 
The following are instances experienced at the Bureau, where filter papers containing large amounts of degraded cellulose have interfered with specific analytical determinations:

Material extracted from paper of poor cellulosic quality sometimes causes incomplete precipitation of $\mathrm{R}_{2} \mathrm{O}_{3}$. The reaction is probably like that of certain organic hydroxy acids that are sometimes used in chemical analysis to prevent the precipitation of iron and aluminum hydroxides.

The extracted material seriously interferes in oxidimetry by acting as a reducing agent. The determination of calcium oxalate with permanganate, and cases where potassium dichromate is used as an oxidizing agent are examples.

Degraded cellulose sometimes causes erroneous results in colorimetry. For example, an inferior paper may produce a yellow color in the colorimetric method for the determination of chromium, even though chromium is absent.

Mention should be made also that even cellulose of good quality is slightly soluble. ${ }^{6}$ This is shown for filter paper by the data in table 7 for two papers having alpha-cellulose contents of 65 percent and 97 percent, respectively. Fifty milliliters of the solvents indicated in table 7 were passed at room temperature through $7-\mathrm{cm}$ circles fitted in ordinary 60-degree funnels. This procedure cannot be considered as a quantitative method for the determination of the solubility of cellulose, but was selected because it simulated actual filtering conditions. These data are merely illustrative of what might occur, because the

TABLE 7.--Solubility of cellulose of filter papers

SAMPLE 1, ALPHA-CELLULOSE $=65$ PERCEN'T

\begin{tabular}{|c|c|c|c|}
\hline Solvent ${ }^{1}$ & Water & $\begin{array}{l}\text { Sulfuric } \\
\text { acid, } \\
0.2 N\end{array}$ & $\begin{array}{c}\text { Sodium } \\
\text { hydrox- } \\
\text { ide, } \\
0.2 \mathrm{~N}\end{array}$ \\
\hline $\begin{array}{l}\text { Milliliters of } 0.1835 \mathrm{~N} \text { potassium dichromate } \\
\text { required to oxidize cellulose in filtrate.... }\end{array}$ & 0.7 & 0.6 & 1.3 \\
\hline Milligrams cellulose in filtrate & .9 & .7 & 1.6 \\
\hline
\end{tabular}

SAMPLE 2, ALPHA-CELLULOSE $=97$ PERCEN'T

\begin{tabular}{r|r|r|r}
\hline $\begin{array}{l}\text { Milliliters of } 0.1835 \mathrm{~N} \text { potassium dichromate } \\
\text { required to oxidize cellulose in filtrate }\end{array}$ & & & \\
Milligrams cellulose in filtrate..... & 0.2 & 0.2 & 0.6 \\
\end{tabular}

${ }^{1} 50 \mathrm{ml}$ passed through $7-\mathrm{cm}$ circles.

${ }^{6}$ James Strachan, Solubility of cellulose in water, Nature 141, 332 (1938). chemical nature of cellulose is so complex that its degree of solubility is not a simple function of the amount of degraded cellulose present, except under the conditions of the method for the determination of alphe-cellulose. The cellulose in the filtrates was determined by oxidation with potassium dichromate in acid solution.

An interesting phenomenon concerning cellulose solubility was observed by passing a second $50-\mathrm{ml}$ portion of solvent through the same circle of filter paper in the above procedure. One-fourth to onehalf as much cellulose was dissolved by the second $50-\mathrm{ml}$ portion as by the first. This slight but persistent solubility of cellulose, even after several washings, has been observed by Strachan. ${ }^{7}$

It is quite clear that filter paper cannot be considered as an inert material even toward water.

\section{Recommended Standards}

As filter papers containing degraded cellulose are usually unstable in storage and may cause errors in analytical work, the necessity for cellulose of high quality is indicated. Quality of cellulose is defined satisfactorily by alpha-cellulose content and copper number. It is likewise known by experience with papers in general that if the acidity is too high, on aging they will become brittle and the cellulose will become degraded. Acidity expressed as the $\mathrm{pH}$ value of an aqueous extract of the paper is a satisfactory safeguard in this respect.

From an inspection of the test data, it would appear that an alpha-cellulose content of not less than 95 percent, a copper number of not more than 0.5 , and a $\mathrm{pH}$ value of not less than 6 , could be required. The other important properties for satisfactory performance of the papers are considered to be ash content, strength, time of flow of water, and retentiveness of precipitates.

With regard to the ash content of the double acid-washed papers, only one showed an ash content as great as $0.3 \mathrm{mg}$ per $11-\mathrm{cm}$ circle, and only three others an ash content above $0.1 \mathrm{mg}$ per $11-\mathrm{cm}$ circle. It appears that $0.1 \mathrm{mg}$ of ash in an $11-\mathrm{cm}$ circle should be a reasonable maximum requirement.

Qualitative papers usually are not acid-washed and therefore contain more mineral matter than the acid-washed papers. The data in table 1

${ }^{7}$ See footnote 6. 
show that the highest ash content for any of the unwashed papers was $4.2 \mathrm{mg}$ per $11-\mathrm{cm}$ circle, and only 6 of the 27 papers had an ash content greater than $1 \mathrm{mg}$ per $11-\mathrm{cm}$ circle. A reasonable value for maximum ash content for qualitative papers should be $1.0 \mathrm{mg}$ per $11-\mathrm{cm}$ circle.

It is difficult to make definite recommendations for time of flow and retention of precipitates, as retention is not a simple function of time of flow, and values for time of flow show such great variation, as shown in tables 1, 2, 3, and 4. Factors that may influence the time of flow and retentiveness are the physical condition of the fibers, density, thickness, formation of the sheet, and probably others not mentioned. In view of the many variables it is very unlikely that retentiveness should bear a simple relation to time of flow.

The data on time of flow of water and retention of barium sulfate bear out this point. In an extreme case the retention of barium sulfate was incomplete for a paper with an average time of flow of 80 seconds, and complete for a paper, made by another manufacturer, with an average time of flow of 14 seconds.

A recommended procedure for selecting a filter paper of the proper speed and retentiveness is to find by trial and error the fastest paper that retains the material in question. Inasmuch as manufacturers usually err on the side of safety in their recommendations in this respect, it is often advisable to experiment with faster papers than recommended if the number of filtrations warrants the trouble. As a general guide for filter papers for ordinary use, maximum times of flow may be set as follows: papers for coarse precipitates, 20 seconds; papers for medium precipitates, 40 seconds; and papers for fine precipitates, 85 seconds for unwashed papers, and 150 seconds for acid-washed papers.

With regard to the bursting strength, it is recommended that all filter papers have a minimum wet-bursting strength of at least 3.0 and preferably 4.0 points. It is true that some of the papers tested had a lower bursting strength, but this is not desirable, especially if the papers are to be used in a Buechner funnel. If papers of unusual strength are desired, attention is directed to the qualitative and quantitative papers that have been "hardened" to increase their strength.

A type of nonuniformity that is very important is the presence of pinholes in filter paper. As this is something that cannot always be discovered in the testing of random samples, the analyst should inspect each circle by transmitted light before use.

The recommended standards are necessarily based on the present quality of filter papers. The usual experience of the Bureau has been that when an investigaton of this kind shows a large variation in desirable properties of materials, a general improvement in their quality results. Improvement of the condition of the cellulose in filter papers and in their time of flow are particularly desirable, and a comparison of the test data for papers of different manufacturers indicates that such improvement is feasible.

The assistance of Thelma L. O'Brian, Alice J. Padgett, and $\mathrm{V}$. Worthington in performing the testing reported herein is gratefully acknowledged by the authors.

Washington, September 11, 1946. 